\title{
Design Sprint for SMEs: an organizational taxonomy based on configuration theory
}

Stefano Magistretti1, Claudio Dell'Era2, Nicola Doppio3

1,2School of Management, Politecnico di Milano - Piazza L. da Vinci, 3220133 Milano Italy

3 HIT - Hub Innovazione Trentino, Trentino Innovation, Trento, Italy

This is a post-peer-review, pre-copyedit version of an article published in Management Decision. The final authenticated version is available online at: https://doi.org/10.1108/MD10-2019-1501

Please cite as: Magistretti, S., Dell'Era, C. and Doppio, N. (2020), "Design sprint for SMEs: an organizational taxonomy based on configuration theory", Management Decision, Vol. 58 No. 9, pp. 1803-1817. https://doi.org/10.1108/MD-10-2019-1501

\begin{abstract}
Purpose - Design approaches to innovation are booming in both the academic and practitioner worlds. Tech giants are proposing different methodologies to develop technological innovation leveraging design principles, e.g., Amazon with working backward, and Google with Design Sprint. However, little is known on the role of these methodologies in managing the knowledge translation among different stakeholders. This paper aims to investigate how Design Sprint approaches can face digital challenges and foster collaborations.

Design/methodology/approach - Through interviews and participatory observations of ten exploratory cases of SME adoption of the Design Sprint methodology, data were collected, organized, clustered, and then validated. Furthermore, by adopting a configuration theory perspective, the data have been processed to contribute to the emergence of two Design Sprint organizational taxonomy.
\end{abstract}

Findings - Competences, type of design challenge, and the process followed emerge from the cases as key drivers of different Design Sprint configurations. Moreover, the configuration theory helped in identifying two Design Sprint taxonomies named Willing and Wondering configurations. Finally, the paper provides managers with practical guidelines on how to leverage these configurations to make this approach more effective for SMEs and how this method helps the knowledge translation.

Originality/value - The value and originality of the paper are in defining Design Sprint from a theoretical point of view and offering practical guidelines on how to adapt it to the particular context of collaborative digital environments of SMEs. Moreover, it contributes to enlarging the relevance of configurational theory in the creative industries.

\section{Keywords}

Design Sprint, Configuration Theory, SMEs, Design Thinking, Knowledge sharing 


\section{Paper type}

Research Paper

Special Issue on "KNOWLEDGE TRANSLATION IN COLLABORATIVE ENVIRONMENTS."

\section{Introduction}

The digital transformation of several businesses and society has enormous growth potential. Companies can leverage advanced digital technologies and their strong presence in traditional sectors to seize the range of opportunities that digital technologies offer (Nambisan et al., 2017). Digital transformation is characterized by the integration of advanced technologies and physical and digital systems, the predominance of innovative business models and new processes, and the creation of smart products and services (Sanasi et al., 2020). Currently, many businesses are not taking full advantage of these technologies (Magistretti et al., 2019b).

Today everyone wants to be digital and fully exploit the opportunities that digital technologies offer. The first step is truly understanding what this means and how digital technologies can be properly exploited to design meaningful products and services (Magistretti et al., 2020). As Urbinati et al. (2018) note, digital transformation has undoubtedly become a key enabler of innovation as evidenced by the numerous firms that use digital technologies to manage their innovation processes (Nambisan et al., 2017). This sound theoretical effort around how digital technologies facilitate innovation processes has resulted in numerous attempts to provide conceptual strategic and innovation frameworks. Digital technologies such as Big Data Analytics, Internet of Things, Artificial Intelligence, Rapid Prototyping, Idea and Knowledge Management, and so forth, can also empower different phases of the knowledge transformation process as well as in the innovation processes (Raven et al., 2011).

In this context, SMEs can compete with large organizations by leveraging the opportunities from digital technologies thanks to open innovation and crowdsourcing, but they need to 
empower their skills in interpreting, adopting, and innovating such technologies (Verganti et al., 2017). Moreover, when they have to deal with the knowledge translation, new approaches that can foster this interpretation process and transformation can be beneficial (Simeone et al., 2017). The emergence of new paradigms, such as human-centered design, participatory design, and especially Design Thinking (Brown, 2008), have marked the transforming role of design in the field of innovation studies. This phenomenon lead to the emergence of new more hybrid approaches, such as Design Sprint, that brought Design Thinking principles in the realm of digital contexts (Knapp et al., 2016). Similarly, to Design Thinking, Design Sprint promotes innovation through iterative and experimental processes favored by digital technologies, albeit moving in significantly different directions.

Nevertheless, the adoption of such approaches might require different configurations to exploit better all the opportunities provided by technologies (Reck, and Fliaster, 2018). As far as the authors' knowledge, a taxonomy for this kind of innovative approach is still missing in the literature. Configurational theory state that configurations are defined as recurring clusters of organizational strategies, structures, and processes (Miller, and Friesen, 1978). Notwithstanding this, little is known about how configurations might influence performances. There are researches in hospital settings (Ketchen et al., 1993) in no profit and young firms (Steffens et al., 2009). Still, it is not clear in a high-tech environment and especially in creative industry, how different configurations might influence performances. Thus, as far as the authors' knowledge, little is known on the configurations that would support this kind of innovation approach. In doing so, a configurational theory framework (Meyer et al., 1993) is adopted to study the taxonomies emerging from the investigation of different adoptions of Design Sprint methods into SMEs. From an empirical perspective, we rely on data collected during a pilot execution of an initiative aimed at supporting SMEs in adopting design sprint in new product development. Thus, two different configurations emerge, Willing and Wondering, 
that inspire managers on how to exploit the best of design sprint methodology accordingly to the context that they are facing. The paper introduces also a few managerial implications and theoretical contributions.

\section{Literature review}

\subsection{Design Thinking}

Scholars and practitioners acknowledge the central role of design as a driver of innovation and change (Brown, 2008; Martin, 2009; Liedtka, 2015). The importance of design as a source of value creation had been scrutinized for decades. However, most of these investigations address design as the aesthetic and symbolic dimension of products, i.e. design as "form", identity and emotions, imparting design a marginal role in the realm of innovation studies (Verganti, 2009, 2017; Dell'Era and Verganti, 2010; Magistretti et al, 2019a). What has driven the steep growth of attention to design in the last years in the business community is a change in perspective: design not only as an aesthetic driver of innovation, but as a whole innovation management practice, a new set of processes, mindsets, capabilities, and organizational settings.

Çetinkaya et al. (2013) attempt to clarify the concept of Design Thinking, distinguishing between its academic development (defined "designerly thinking") and its more practical development, particularly in the business realm, now known as Design Thinking. Çetinkaya et al. (2013) also provide a brief projection of how Design Thinking became a trend among management scholars: according to their research, it started to gain attention in the management realm in the 1980s. This paradigm is one of the preferred modalities to solve wicked, ill-defined problems, since it is a problem-solving approach relying on discovery in advance of issues and needs, on expanding the boundaries of both the problem and solution, and on igniting creativity and confidence in problem solvers (Dell'Era et al., 2020). It can be described as a visualizationintensive problem-solving mode, which heavily exploits the potentialities of drawings, sketches, and graphic representations to rapidly translate knowledge into forms that are more 
useful for specific context (Simeone et al., 2017). Visualizing is the main sense-making modality in Design Thinking and one of its distinguishing features. Moreover, there is an ongoing debate on the principles, practices and tools associate with different kinds of design thinking (Dell'Era et al., 2020). Indeed, it has been recognized that different aims of projects might influence the decision to undergo one or another type of Design Thinking, from Creative Problem Solving (Brown, 2008) to Sprint Execution (Knapp et al., 2016) or Innovation of Meaning (Verganti, 2017). Thus, the debate on the different principles and themes is still evolving to the point that a better understanding of the impact that this might have on the configurational organization (Meyer et al, 1993) at both individual and team levels might be of interest of both practitioners and academics.

In addition to this, as far as the author knowledge, less is known in the design thinking field about the role that this methodology can have in the knowledge translation problem and how the iterative human-centered approach can facilitate this process of transformation of abstract knowledge in tangible forms.

\subsection{Design Thinking in the digital era: Design Sprint}

The growing number of publications in academic journals (Brown, 2008; Micheli et al., 2019) show that the Design Thinking debate is still evolving and sometimes controversial. Different aspects of Design Thinking are evolving, it clear to academics and practitioners that there is no one single interpretation of it (Dell'Era et al., 2020). In particular the idea that considering different needs different approaches are required shows how Design Thinking in digital era might change and adapt to be more agile and flexible (Zeratsky, 2016). In particular this emerging approach of design thinking is defined by academics Sprint Execution and it is routed on both Design Sprint approach defined by Google in 2016 and agile and lean principles.

Agile methods are booming in many industries due to the explosion of digital transformation and the subsequent need to deliver new digital experiences (Magistretti et al., 
2019c). Not only software developers and integrators, such as Microsoft, or Oracle, extensively adopt agile practices, but also new players specialized in developing new user experiences (UXs) and user interfaces (UIs), leveraging the opportunities offered by agile methods, such as Amazon. Particularly in this last segment, a growing field of research is attempting to understand what the future of new product development could be. This approach has grown in relevance since the publication of Eric Ries' (2011) The Lean Startups. The approach is grounded in the Minimum Viable Product concept based on designing and crafting a product to launch on the market that is a simpler yet functional version of the final product. Indeed, this approach to NPD allows collecting feedback from the market earlier than traditional approaches, such as stage gate, and allows firms to reduce uncertainty of market acceptance (Colombo et al., 2013). This evolution toward more flexible and agile approaches gave rise to research related to agile stage gate methodologies (Cooper and Sommer, 2016). Moreover, this tension toward new hybrid models to manage innovation put under discussion the traditional processes of knowledge translation (Capaldo et al., 2017). Indeed, more flexible processes of search and recombination are needed (Savino et al., 2017). This growing attention toward new iterative and diverging approaches also led to the evolution of the design thinking paradigm. Indeed, in 2016, Google Ventures, published a handbook on the Design Sprint methodology based on some Design Thinking and Lean Start up concepts to support both the incubated startups and big projects managed by Google itself (Knapp et al., 2016).

In particular, the methodology leverages five principles grounded in both the Design Thinking and the agile literature streams (Zeratsky, 2016). Indeed, this shows the strong link between Design Sprints and Design Thinking as a broader methodology to foster innovation. The first principle is that sprints, help you start, clearly showing the link with the startup world; when this challenge is of prime importance and the firm does not know where to start, Design Sprint is a good methodology to address such wicked problems (Rittel and Webber, 1973). The 
second refers to transferring knowledge from the abstract to the concrete; too often companies are unable to foresee the value of the final product, and hence need to integrate and experiment with the solution as fast as possible, especially its technological dimension (Thomke, 2003). The third is framed as keeping the focus on what is important, based on the concept of creating creative confidence within the team (Kelly and Kelly, 2013). The fourth is related to forcing crisp decision-making with the purpose of creating and crafting a new meaningful direction shared and agreed by all team members because it emerges from deep criticism (Verganti, 2017). Finally, the last is sprint as a process that encourages fast follow-up (Ries, 2011). Similarly, to MVP and the agile methodologies, in Design Sprint, the final product is far from ready to be launched on the market.

Emerging from the literature review is the growing interest of both practitioners and researches in the methodology. Indeed, the methodologies seem yet to be discussed and adopted in SMEs (Fernández-Mesa et al., 2013). As SMEs are a particular type of firm in terms of the principles and practices adopted (Larsen and Lewis, 2007), a study that sheds light on this interesting gap would thus be beneficial for both practitioners and academics. Moreover, what seems lacking in the extant literature about Design Sprint is a knowledge of the configuration dimensions of this approach (Jung, 1991). In the first framing of Design Sprint by Google, there has been a definition of the team but, less is known on the organizational configuration that might support the diffusion of it (Meyer et al., 1993).

\section{Conceptual Framework}

The paper aims at contributing to Design Sprint adoption in SMEs by adopting a configurational theory perspective. As far as the author's knowledge and has reported above, this perspective has been neglected by academics in the design field. Shed lights on how different configurations might influence the creative processes are the objective of the research. 
Indeed, given the relevance of configurational theory (Mintzberg, 1979) knowing more about how peculiar are the configuration in this creative environment might contribute to both theory and practice. Indeed, even though it has been recognized as interesting for managing strategy formulation (Miller and Friesen, 1978) and in understanding performance management (Ketchen et al., 1993), less is known on how configurational theory might impact design management approaches.

Configurational theory unveiled how there are imperatives that are the cause and configurations that are the effects of strategic decision (Miller, 1987). Theory shows that the imperatives are four: environment, structure, leadership, and strategy. Depending on the combination of these external factors, configurations might change. Different technologies or environmental challenges, as well as control of tasks, CEO motives, and strategic plans, are imperatives that influence the configurations (Miller, and Friesen, 1984). Extant literature on configurational theory showed how these interactions of imperatives give rise to different configurations. Academic researches highlighted how configurations allow academics and practitioners to make sense of the outside worlds by sorting things discrete and relatively homogeneous in configurations (Meyer et al., 1993). By adopting the configurational theory framework, we aim at understanding how different clusters of comparable components at the social system level emerge, what are the reciprocal relationship among attributes, and show the emergence of punctuated equilibrium. Therefore, we seek to answer the following research question: How can different Design Sprint configurations be adopted to manage knowledge and spark innovation in digital collaborative challenges in SMEs?

\section{Research Methodology}

\subsection{The research method}

Given the aim of this study and the research question, the participant observation is deemed the most appropriate (Spradley, 2016). Indeed, the complexity of the phenomenon and the 
exploratory nature of the investigation suggest adopting a qualitative research approach and conducting interviews and observation on inspiring cases to dig deeper into this emerging approach to innovation (Spradley, 2016). Furthermore, the adoption of such methodology in directly get empathy with users by ethnographically observing them allow us to deal with the "how" question underpinning the research (Canterino et al., 2018). In particular, the study aims to enrich both practitioner and researcher knowledge on the practical way the Design Sprint methodology can be adopted not only by startups but also by other companies. Moreover, by investigating the adoption of such methodology in real projects, by combining direct interviews and observations, typical techniques of a participatory observation (Musante, and DeWalt, 2010), shed light on the way different SMEs adopted this approach. Thus, the study leverages both primary and secondary sources that provide the opportunity to compare and contrast the framing of the Google Ventures approach with its new evolution.

\subsection{Empirical setting}

The study investigates the experimental adoption of Design Sprint by a regional public innovation and technology transfer agency in Northern Italy as a tool to support innovation in digital SMEs. The agency has a strong track record in supporting user-centric research and innovation in a Living Lab setting - especially in EU-funded R\&D project consortia (Dell'Era and Landoni, 2014; Dell'Era et al., 2019). Accordingly, the initiative, UX Challenge ${ }^{1}$, connected digital companies with young UX designers and interaction designers to improve the user experience of apps and software in a collaborative environment over a period of two days. The companies and the young talent (so-called "solvers") were selected via a strict public selection process. Companies applied to the initiative with own products that had user experience issues or opportunities to be sought. Many were consumer mobile apps in need of

\footnotetext{
${ }^{1}$ https://www.trentinoinnovation.eu /ux-challenge-2/
} 
optimizing user flows and the usability of interfaces. Five products were selected from among the fourteen applications received. Students and young professionals, mentored by experts, teamed up to solve the "UX challenges" by executing a Design Sprint over the two days of the initiative. Two teams were assigned to each product and company, although addressing different challenges. All teams worked separately and competed for a final prize. Expected teamwork outputs included newly designed user flows, interface wireframes and mockups, interactive prototypes, and insights from the user testing phases.

\subsection{Data collection and analysis}

The UX Challenge proved a perfect data collection source. The competition was set up as a two-day hackathon where the different SMEs proposing the challenge would adopt the Design Sprint methodology to solve their user experience problems.

Indeed, given our research question and interest in better understanding SMEs and their relation with Design Sprint, this setting was ideal to study the phenomenon. Accordingly, the authors took part in the Challenges as observers, and during the two days of observations had the opportunity to interview and interact with more than 70 people participants including company representatives (10), solvers (36), mentors (10), organizers, partners, and experts involved in the jury (10), and take notes on the way the methodology was adopted and experimented. Organizers were also interviewed after the event, to commenting on results and helping researchers analyzing data.

All the material collected was transcribed and coded in a unique database that became the sources of knowledge to answer the research question. All the information was clustered according to the SMEs and the related products as well as the analysis of the different imperatives were conducted, according to the configurational theory, environmental, structure, strategy, leadership, and strategy. In particular, given our interest in understanding how the 
design sprint was adapted to fit the challenges related to digital products and technologies in SMEs, a detailed analysis of the ten sprints was conducted. Moreover, we observed the sprints and analyzed the material to cluster the information according to three main dimensions: challenges (A), competences (B) and processes (C).

The challenges (A) variable was classified according to Colombo et al. (2013) into ideation or trial-and-error. The ideation cases were the challenges where the objective was to propose a brand-new concept or feature for a product or a service. In contrast, the trial and error cases were the ones where the challenge aimed at solving existing problems on preexisting versions of the product.

The competence variable (B) considered both the team background (focused, or spread) and mentor seniority (junior vs senior) (Tushman and Nadler, 1986). This variable allows us to map the different leadership imperative adopted and how they influence the configurations (Miller. 1987). In particular, if the background of the team member was coherent and homogeneous, the focused label has been assigned, while the spread was used in all the others. In terms of mentor seniority, if the mentor had previous experience in supporting a team, or in facilitating user-centered design processes, the senior label was used; the junior has been used in the remaining cases. Finally, the process $(\mathrm{C})$ variable refers to the critical characteristics of each executed design sprint as a process: the perspective adopted (inside-out vs outside-in) (Verganti, 2009), and the embodiment (prototyping vs pretotyping ${ }^{2}$ ) (Hillgren et al., 2011; Cooper and Sommer, 2016). In line with the structure imperative (Miller and Friesen. 1978) and the strategy one (Meyer et al., 1993), the process variable, maps the interactions among phases and perspectives. In particular, by perspective adopted, we mean the fact that the design sprint could either move from an initial user-testing of a pre-existing solution (outside-in), or by designing the new direction independently by the feedback coming from the use (inside-

\footnotetext{
${ }^{2}$ https://www.pretotyping.org
} 
out). For what concerns the embodiment, prototyping means creating something functional that resembles the real product, while the pretotyping means to embody a rough hypothesis, just for the sake of visualizing the team assumptions (e.g. development of user personas, user scenarios, interface sketches and early wireframes).

Finally, the Challenge ended with an evaluation of the teams' outputs by a jury. This information was also included in the database as a measure of the performance achieved. The repository of these data was then analyzed by the authors into two subsequent phases. The first aimed at understanding commonalities and differences in the way the SMEs adopted the methodologies, and of course, the results achieved. The second in looking for patterns of adaptation and adoption of the methodologies in managing knowledge and allow the collaboration to happen.

Table I Data collection.

Table I. Data Collection

\begin{tabular}{|c|c|c|c|}
\hline & Source Nature & Data Gathered & $\begin{array}{l}\text { Inclusion in the } \\
\text { Database }\end{array}$ \\
\hline \multirow[t]{2}{*}{ Primary sources } & $\begin{array}{l}\text { Semi structured } \\
\text { Interviews }\end{array}$ & Around 40 & $\begin{array}{l}\text { Transcribed in more } \\
\text { than } 100 \text { pages }\end{array}$ \\
\hline & $\begin{array}{l}\text { Participatory } \\
\text { Observation }\end{array}$ & More than 48 hours & $\begin{array}{l}\text { More than } 40 \text { Pictures } \\
\text { and more than } 30 \\
\text { pages of notes }\end{array}$ \\
\hline \multirow[t]{2}{*}{$\begin{array}{l}\text { Secondary } \\
\text { Sources }\end{array}$} & $\begin{array}{l}\text { Information about the } \\
\text { companies }\end{array}$ & $\begin{array}{l}\text { Company Website } \\
\text { analysis }\end{array}$ & $\begin{array}{l}\text { Biographical data for } \\
\text { the } 10 \text { companies } \\
\text { involved }\end{array}$ \\
\hline & Press releases & $\begin{array}{l}\text { Newspapers, digital } \\
\text { and physical }\end{array}$ & $\begin{array}{l}\text { More than } 25 \text { pages of } \\
\text { press releases related to } \\
\text { the companies and the } \\
\text { Challenge }\end{array}$ \\
\hline
\end{tabular}

\section{Empirical results}

In this section, we report the results of the different challenges of the five SMEs by highlighting the main dimensions that emerged. 


\subsection{Adopting Design Sprint in designing Digital Applications of SMEs}

Five digital products presented by the SMEs (software house, app developers, and web agencies) and ten teams took part in the initiative. Each product came with two "UX challenges" so that each team deployed a sprint over a specific UX design problem. The selected products were the following: two mobile apps (home banking and supermarket); a fixed kiosk app to be utilized by athletes; an augmented reality system for technicians; a chat bot allowing citizens to interact with the public administration.

The five aforementioned apps entered the initiative with completely different maturity. Some were largely established on the market and so the focus of the challenge was on optimizing existing user flows or designing new features. Differently, others came to the initiative as prototypes or even concepts: in this case, the challenges related more to the design of the product's user experience, including overall user journey and flows, information architecture, interface wireframes and mockups.

Ten Design Sprints for the five products were executed over the two days, each with a clear UX design goal. The process followed by all the sprints included: (i) identifying the design challenge (scoping the Sprint); (ii) ideating possible solutions; (iii) deciding which solution to develop; (iv) prototyping the chosen solution; (v) testing the prototype.

All the phases were carefully scheduled in the 2-day teamwork agenda. The interviews show that in the case of low-maturity products, the sprint tended to give more room to ideation and prototyping work. Differently, in the case of existing products, the sprint focused more on finding, understanding, and fixing current UX issues. Indeed, in such cases, the user testing phase was brought forward to the beginning of the sprint so as to inform a re-design rooted in sound evidence from user testing. 
"While reviewing the applications sent by companies we noticed that many submitted products were already on the market, so they didn't need a thorough design work... they just wanted to use the UX Challenge to spot usability issues and improve the overall user experience of their product. Then we decided that in some cases it made more sense to kick-start the sprint with a user testing, just to validate the UX problems that we saw during the application phase, but also to give a clear goal and scope to the team."

\section{UX Challenge Organizer}

More than thirty-six solvers took part in the process selected via a public call two months before the initiative when the CVs were evaluated and ranked. Teams were formed by the organizer balancing the solvers' previous experience, assigned one product and one challenge prior to the initiative. Companies proposed the challenges in the application form. Teams were given a half-day's training on the sprint some days before the initiative. They were then supported by two expert mentors whose function was to inspire and supervise the teamwork. Mentors were actually assigned to products not to teams directly, which meant each team could count on the help of two mentors. Accordingly, personnel from companies joined the 2-day initiative to support the teams.

\subsection{Performing Design Sprint in designing digital applications in SMEs}

After reporting the data on the characteristics of the different challenges, we triangulated this information with the score given to each project. Table II reports the classification of the different sprints in terms of Challenge, Competence and Process characteristics and the score measured by both companies and external jury.

Some interesting insights emerge from this table. First, it seems that there is a link between mentor seniority team composition and the kind of challenge faced. The reason for this 
configuration turned out to be the following: companies bringing a trial-and-error challenge had rather specific expectations from sprint (to solve a certain UX problem); for such reason organizers decided to match those teams with senior mentors and solvers with a human computer interface background, in order to provide more support and increase the chances for a successful sprint (while, in case of ideation challenges, junior mentors and solvers with a mixed background were presumably deemed to provide adequate support). While already discussed in the entrepreneurship literature, this has not been fully explored in the creativity and design literature. The emergence of this connection suggests that different configuration might support differently the Design Sprint projects. Indeed, researches focus on the power of design thinking as a good approach to manage the absence of mentors (Brown, 2008), but the role of mentors in design thinking approaches is yet to be properly addressed. However, in contrast with the choice of organizers, the below quote reports that since companies where not aware of the potential raceable output, the initial framing of the problem was very hard for the participants, because the knowledge transfer was not easy.

"The challenge came more like a user research question, rather than a UX problem: indeed, the company was interested in understanding what conversational style the chatbot should have... e.g. formal, as a public administration, or friendly, as normal chats interactions. Overall, the initial meeting did not help us solvers in scoping the challenge finding a problem and having a clear idea about what kind of results they were meant to achieve."

Member of Team 3.1

This is unsurprising when considering the theoretical definition that academics propose. With ideation, scholars define the challenges characterized by low technical uncertainty and 
high market uncertainty (Terwiesch and $\mathrm{Xu}, 2008$ ). Differently, with trial-and-error, they define problems characterized by high technical uncertainty and low market uncertainty (Jeppesen and Lakhani, 2010).

Second, in terms of the process dimensions, interesting to note is that the majority of projects followed an inside-out approach, while the projects that followed the outside-in approach (user testing at the beginning of the sprint) are ranked $3 \mathrm{rd}$ and $4^{\text {th }}$ (with equal merit), hence in the higher ranking.

"Our product did not come with a clear challenge brief: the company did not know where to scope the sprint. At the beginning we though that the only way to run an effective design sprint was to look more deeply into the current version of the product before the sprint. But then we understood that since there was not time or budget to do this, the only way to do so was to shape that specific sprint in a manner that it could start by testing the as-is version of the app."

Mentor of Team 5.2

This way, anticipating the user testing at the beginning of the sprint (normally its last phase), allowed to mitigate the risks related with a lack of knowledge transfer from the SMEs to the team, as the two outside-in projects resulted amongst the three top performers.

Finally, the investigation suggests that in the Design Sprint methodology adapted to the SME context, the tension toward prototyping seems to predominate instead of pretotyping. This is surprising when considering the centrality of iteration and tension to create the embodiment of the solution, which is far from considered a prototype (from Greek, first type) of the solution (Zeratsky, 2016). This implies that for SMEs, the tension toward crafting an early solution is more relevant than the creation of just enough of the final solution to learn 
from the market. This is another difference that emerged compared to the traditional Design Sprint.

"Our home banking app is actively used by 600 thousand consumers: we need to be very careful with designing new functionalities. At the moment we prefer to optimise the usability of the existing version. [..] I can give these interface prototypes to our developers and they understand what they need to change."

Representative from company 3

\section{Discussion}

Reading the empirical results through the configurational theory framework allowed us to shed light on how different design sprint configurations are emerging in response to different imperatives. This is an under-researched topic. We observed that two out of three variables utilized in the analysis (B-Competences, and C-Process), were strictly intertwined with each other, although it is still not clear to what degree they respectively contributed to the effects we observed, and, beyond that, possibly affected each other. Indeed, Table II suggests the emergence of two different configurations for adopting design sprints in SMEs. By adopting the configurational theory (Meyer et al., 1993), Table II proposes two emerging taxonomies. The different combination of the imperatives at the structure and leadership dimensions (Miller, 1987) (e.g. Competences and Process) shows the emergence of two configurations emerging from the data, that we called Willing Configuration and Wondering Configuration for Design Sprint in SMEs. The Willing one (Projects: $3.1 ; 3.2 ; 5.2 ; 4.1$ ) shows how a focused team, with senior mentors, adopting an inside-out perspective and aimed at prototyping a solution, can shape a conclusion in a more leapfrog approach. This configuration is a combination of different attributes that shows a homogenous cluster of interactions among different 
components of the team organization. In particular, the Willing configurations is the organizational cluster that group those teams leverage seniority and focalized backgrounds to speed up the process of envisioning new solutions and embodying new scenarios in prototype to iteratively experiment the intuitions generated along with the creative sessions. So, the Willing Configuration includes highly-skilled and experienced individuals who, through mechanisms of mutual adaptation and a flat hierarchy, channel their efforts into experimentation processes. The second taxonomy emerging from the analysis (the Wondering one, including projects: $1.1 ; 1.2 ; 2.1)$, shows how a spread team background, a junior mentor, an inside-out approach can be utilized to allow SMEs to deliver pretotypes ponder user's desirability of future scenarios. Indeed, this second configuration shows a more naïve and explorer mindset that the organization should embrace due to low seniority and the eagerness to propose a new embryonic and possibly radical solution to a wider challenge. Thus, Wondering Configuration is composed by individuals that are newbies with different backgrounds, and thus, embracing pretotyping as a medium is able to align themselves to solve challenges. So, Wondering Configuration includes the collaboration between beginners who, through embodying creative ideas in concrete solutions, channel the resources into execution processes.

These two emerging taxonomies contribute to the theory and practice by showing how different dimensions of competences and processes can support the identification of different configurations (Jung, 1923). The investigation enriches both the configuration theory by showing how it might help in understanding the configuration in teams and small groups of interaction regarding the different distinctive competencies needed for different challenges (Meyer, 1991). Moreover, it shows how imperatives (Miller, 1987) are adapted in design management literature in terms of competences and processes. In addition, it enriches Design Sprint literature about the recognition of different flexible and adapting configurations as well 
as different ways to transfer knowledge. Moreover, the adoption of prototype for embodying or pretotype might also inform researchers on the different approach toward knowledge transferring (Simeone et al., 2017). Indeed, different embodiment would transfer information differently, prototype in a more definitional way the pretotyping in a more explorative way.

Table II. Taxonomies of the different Organizational Configurations emerging from the 10 sprints in the UX Challenge

\begin{tabular}{|l|l|l|l|l|l|l|l|c|}
\hline & (A) Challenge & \multicolumn{2}{|c|}{ (B) Competences } & \multicolumn{2}{|c|}{ (C) Process } & \multicolumn{2}{|c|}{ Score } & Configurations \\
\hline Project & Typology & $\begin{array}{c}\text { Team } \\
\text { Background }\end{array}$ & $\begin{array}{c}\text { Mentor } \\
\text { Experience }\end{array}$ & Perspective & Embodiment & Points & Ranking & Taxonomies \\
\hline 3.1 & Trial-and-error & Focused & Senior & Inside-out & Prototyping & 4.42 & 1 & Willing \\
\hline 5.1 & Trial-and-error & Spread & Senior & Outside-in & Prototyping & 4.08 & 3 & \\
\hline 4.2 & Trial-and-error & Focused & Senior & Outside-in & Prototyping & 4.08 & 4 & \\
\hline 3.2 & Trial-and-error & Focused & Senior & Inside-out & Prototyping & 3.67 & 8 & Willing \\
\hline 5.2 & Ideation & Focused & Senior & Inside-out & Prototyping & 4.33 & 2 & Willing \\
\hline 4.1 & Ideation & Focused & Senior & Inside-out & Prototyping & 3.92 & 5 & Willing \\
\hline 1.1 & Ideation & Spread & Junior & Inside-out & Pretotyping & 3.83 & 6 & Wondering \\
\hline 1.2 & Ideation & Spread & Junior & Inside-out & Pretotyping & 3.67 & 7 & Wondering \\
\hline 2.1 & Ideation & Spread & Junior & Inside-out & Pretotyping & 3.58 & 9 & Wondering \\
\hline 2.2 & Ideation & Focused & Junior & Inside-out & Pretotyping & 2.75 & 10 & \\
\hline
\end{tabular}

Moreover, this study contributes to both the academic and practitioner debates, enriching theoretical knowledge on five dimensions: First, enhancing scholarly knowledge on the role of mentors, the type of challenges and the process that underpin the Design Sprint methodology (Strike and Rerup, 2016). The role of such advisors in mediated sensemaking has been extensively studied (Strike et al., 2016). Given that the mentors in these cases supported the creation of innovation by leveraging different backgrounds, it can be defined as source-based rather than advice-based mentoring (Gino et al., 2012). This is why the seniority of mentors may have generated a higher ranking of the teams. Second, the data shows that there are two types of challenges that have been faced with the Design Sprint methodology in SMEs and they are trial-and-error (i.e., those related to solving problems of existing apps and software), and then the ideation (Colombo et al., 2013) despite the few information reported is difficult to 
state which one would better perform it is although evident that there are different emerging taxonomies of organization configurations. Third, it sheds light on the fact that Design Sprint as presented by Google does not fit every type of company (Zeratsky, 2016). Indeed, if considering the pure Design Sprint process (Knapp et al., 2016), the inside-out perspective should have been the only approach possible. What the cases show is that likely the context, digital challenges, and the fact that SMEs are a particular type of firm, call for collaboration with different stakeholders, hence using the outside-in perspective. Moreover, the typical Design Sprint approach usually shows tension toward product feature validation or incremental innovation, while the evidence shows that there is more value in exploring alternatives. Fourth, it contributes to the ongoing Design Thinking debate by showing that Design Sprint in SMEs might embrace similar mindsets and approaches as traditional creative problem-solving approaches, outside-in perspective (Brown, 2008). Notwithstanding this, in other cases Design Sprints, due to the fact that are run when technological uncertainty is high and market uncertainty was low shows differences with creative problem solving and more similarities with visionary approaches (Dell'Era et al., 2020). Indeed, considering the turbulence of the market due to digitization (Nambisan et al., 2017), we could have expected a more equalized situation were ideation and trial-and-error were more balanced. Fifth, it shows how the knowledge can be transferred by reversing the traditional process of processing, interpreting and transforming (Simeone et al., 2017), to a more trial and error approach.

Final remarks regard the fact that we observed that ideation challenges - those entailing market uncertainty as regarding the validation of new product concepts - were often associated with an inside-out process, entailing pretotyping work. Reflexively, on the other side trial and error challenges - those focusing on technical problems such as solving usability issues always entailed prototyping work (delivering more market-ready outputs - again, following 
intuition). However, only in half of these cases were related to an outside-in process, suggesting that further investigation is needed.

\section{Conclusion}

The paper explores the topic of the Design Sprint methodology in SMEs and how this approach can be shaped to face different challenges when the level of market and technology uncertainty varies. Moreover, by analyzing ten cases, the investigation suggests that Design Sprint cannot be adopted as framed within Google (Knapp et al., 2016) when dealing with SMEs where the perspective is overturned from inside-out to outside-in. This indicates that rather than adopting a traditional Design Sprint, SMEs willing to pursue product's feature optimization or incremental improvements should adopt a sort of "reverse sprint" and start from the end with feedback on the existing as-is version of the product and subsequently go through the sprint phases. This is extremely interesting because it seems to put under discussion the assumption that in Design Sprint, differently from Design Thinking, the role of the user is essential only at the end, supporting the idea that users are also crucial at the start This is an ongoing debate (Dell'Era et al., 2020) that requires more evidence to be accepted academically. Moreover, the evidence emerging from the participatory observation seems to suggest that Design Sprint when it is adopted by SMEs requires a proper organizational configuration that, based on what we have observed, can be either Willing or Wondering depending on its goals.

The investigation contributes to managers' understanding of the design sprint phenomenon in three ways. First, it shows the existence of a different way of running a Design Sprint, the reverse one. In this inside out modality, the configurations of teams should be clearly defined to face ideation or a trial and error challenge. Second, it enriches the understanding of the main dimensions and imperatives that must be controlled in setting the stage of a Design Sprint, such as competences and processes. Third, that there are two ways to embody solutions in Design Sprint processes, prototyping and pretotyping. The first is more traditional as a medium to craft 
a solution, while the latter is adopted in ideation challenges when the sprint is inside-out, and it is not clear the outcome of the process. Thus, crafting the process to support one or the other way of embodying solutions must be a prerogative for managers adopting this methodology.

Finally, we contribute to the academic debate by enriching knowledge on the underpinning dimensions characterizing Design Sprint: competences, challenges, and processes as well as in the understanding of the different configuration taxonomy present in it. This can help both researchers and practitioners understand the way the Design Sprint evolves and should be crafted to be effective in SMEs facing digital challenges. Although this study is exploratory, these insights are extremely relevant to advance the debate around Design Thinking and guide managers in adopting this methodology more consciously. However, some limitations must be considered, such as the regionality of the analysis and typical qualitative methodology limitations.

\section{References}

Brown, T. (2008), "Design thinking", Harvard Business Review, accessed online at https://hbr.org/2008/06/design-thinking

Canterino, F., Cirella, S., \& Shani, A. B. R. (2018). Leading organizational transformation: an action research study. Journal of Managerial Psychology.

Capaldo, A., Lavie, D., \& Messeni Petruzzelli, A. (2017). Knowledge maturity and the scientific value of innovations: The roles of knowledge distance and adoption. Journal of Management, 43(2), 503-533.

Çetinkaya, M., Johansson-Sköldberg, U. and Woodilla, J. (2013), "Design thinking: past, present and possible futures", Creativity and Innovation Management, Vol. 22 No. 2, pp. 121-146.

Colombo, G., Buganza, T., Klanner, I. M. and Roiser, S. (2013), "Crowdsourcing intermediaries and problem typologies: an explorative study", International Journal of Innovation Management, Vol. 17 No. 02, pp. 1350005.

Cooper, R.G., and Sommer, A.F. (2016), "The Agile-Stage-Gate hybrid model: a promising new approach and a new research opportunity", Journal of Product Innovation Management, Vol. 33 No. 5, pp. 513-526.

Dell'Era, C. and Verganti, R. (2010), "Collaborative strategies in design-intensive industries: knowledge diversity and innovation”, Long Range Planning, Vol. 43 No.1, pp. 123141. 
Dell'Era, C., Magistretti, S., Cautela, C., Verganti, R., \& Zurlo (2020), F. Four kinds of design thinking: From ideating to making, engaging, and criticizing. Creativity and Innovation Management.

Dell'Era C and Landoni P (2014). Living Lab: A Methodology between User-Centred Design and Participatory Design. Creativity and Innovation Management, Vol. 23, No. 2, Pp. $137-154$

Dell'Era C, Landoni P and Gonzalez SJ (2019). Investigating the Innovation Impacts of UserCentered and Participatory Strategies adopted by European Living Labs. International Journal of Innovation Management, Vol. 23, No. 5

Fernández-Mesa, A., Alegre-Vidal, J., Chiva-Gómez, R. and Gutiérrez-Gracia, A. (2013), "Design management capability and product innovation in SMEs", Management Decision, Vol. 51 No. 3, pp. 547-565.

Gino, F., Brooks, A.W. and Schweitzer, M.E. (2012), "Anxiety, advice, and the ability to discern: Feeling anxious motivates individuals to seek and use advice", Journal of Personality and Social Psychology, Vol. 102 No. 3, pp. 497-512.

Hillgren, P.A., Seravalli, A. and Emilson, A. (2011), "Prototyping and infrastructuring in design for social innovation”, CoDesign, Vol. 7 No. 3-4, pp. 169-183.

Jeppesen, L.B. and Lakhani, K.R. (2010), "Marginality and problem solving effectiveness in broadcast research", Organization Science, Vol. 21 No. 5, pp.1-18.

Jung, C. G. (1923). Psychological types (HG Baynes, Trans.). London: Kegan Paul.

Kelley, D., and Kelley, T. (2013). Creative Confidence: Unleashing the Creative Potential within Us All, Crown Pub.

Ketchen Jr, D. J., Thomas, J. B., \& Snow, C. C. (1993). Organizational configurations and performance: A comparison of theoretical approaches. Academy of management journal, 36(6), 1278-1313.

Knapp, J., Zeratsky, J. and Kowitz, B. (2016), Sprint: How to Solve Big Problems and Test New Ideas in Just Five Days, Simon and Schuster.

Larsen, P. and Lewis, A. (2007), "How award-winning SMEs manage the barriers to innovation", Creativity and Innovation Management, Vol. 16 No. 2, pp. 142-151.

Liedtka, J. (2015), "Perspective: linking design thinking with innovation outcomes through cognitive bias reduction", Journal of Product Innovation Management, Vol. 32 No. 6, pp. 925-938.

Magistretti, S., Dell'Era, C., \& Petruzzelli, A. M. (2019b). How intelligent is Watson? Enabling digital transformation through artificial intelligence. Business Horizons.

Magistretti, S., Dell'Era, C., \& Verganti, R. (2020). Look for New Opportunities in Existing Technologies: Leveraging Temporal and Spatial Dimensions to Power Discovery. Research-Technology Management, 63(1), 39-48.

Magistretti, S., Dell'Era, C., De Massis, A., \& Frattini, F. (2019a). Exploring the relationship between types of family involvement and collaborative innovation in design-intensive firms: insights from two leading players in the furniture industry. Industry and Innovation, 1-31.

Magistretti, S., Trabucchi, D., Dell'Era, C., \& Buganza, T. (2019c). A New Path Toward a Hybrid Model: Insights from PwC's Italian Experience Centre. Research-Technology Management, 62(5), 30-37.

Martin, R.L. (2009), The Design of Business: Why Design Thinking is the Next Competitive Advantage, Boston: Harvard Business Press. 
Meyer, A. D. (1991). What is strategy's distinctive competence?. Journal of Management, 17(4), 821-833.

Meyer, A. D., Tsui, A. S., \& Hinings, C. R. (1993). Configurational approaches to organizational analysis. Academy of Management journal, 36(6), 1175-1195.

Micheli, P., Wilner, S.J., Bhatti, S., Mura, M., and Beverland, M.B. (2018), "Doing design thinking: conceptual review, synthesis and research agenda", Journal of Product Innovation Management, Vol. 36 No. 2, pp. 124-148.

Miller, D. (1987). The genesis of configuration. Academy of management review, 12(4), 686701.

Miller, D., \& Friesen, P. H. (1978). Archetypes of strategy formulation. Management science, 24(9), 921-933.

Miller, D., \& Friesen, P. H. (1984) A longitudinal study of the corporate life cycle. Management Science, 30, 1161-1183.

Mintzberg, H. (1979). The structuring of organizations. Englewood Cliffs, NJ: Pr

Musante, K., \& DeWalt, B. R. (2010). Participant observation: A guide for fieldworkers. Rowman Altamira.

Nambisan, S., Lyytinen, K., Majchrzak, A., and Song, M. (2017), "Digital innovation management: reinventing innovation management research in a digital world", $M I S$ Quarterly, Vol. 41 No. 1, pp. 223-238.

Raven, R. P., Verbong, G. P., Schilpzand, W. F., \& Witkamp, M. J. (2011). Translation mechanisms in socio-technical niches: a case study of Dutch river management. Technology Analysis \& Strategic Management, 23(10), 1063-1078.

Reck, F., \& Fliaster, A. (2018, July). How to Drive Digital Transformation?-A Configurational Analysis on the Impact of CDOs. In Academy of Management Proceedings (Vol. 2018, No. 1, p. 17471). Briarcliff Manor, NY 10510: Academy of Management.

Ries, E. (2011), The Lean Startup: How Today's Entrepreneurs Use Continuous Innovation to Create Radically Successful Businesses, Crown Business.

Rittel, H.W., and Webber, M.M. (1973), “2.3 planning problems are wicked”, Polity, Vol. 4 pp. 155-169.

Sanasi, S., Ghezzi, A., Cavallo, A., \& Rangone, A. (2020). Making sense of the sharing economy: a business model innovation perspective. Technology Analysis \& Strategic Management, 1-15.

Savino, T., Messeni Petruzzelli, A. and Albino, V. (2017), Search and Recombination Process to Innovate: A Review of the Empirical Evidence and a Research Agenda. International Journal of Management Reviews, Vol. 19: 54-75. doi:10.1111/ijmr.12081.

Simeone, L., Secundo, G and Schiuma, G. (2017) Fostering academic entrepreneurship through design-as-translation to align stakeholders' needs: The MIT SENSEable City Lab case" Technovation, Vol. 64-65, pp.58-67

Spradley, J. P. (2016). The ethnographic interview. Waveland Press.

Steffens, P., Davidsson, P., \& Fitzsimmons, J. (2009). Performance configurations over time: implications for growth-and profit-oriented strategies. Entrepreneurship theory and practice, 33(1), 125-148.

Strike, V.M. and Rerup, C. (2016), "Mediated sensemaking", Academy of Management Journal, Vol. 59 No. 3, pp. 880-905. 
Terwiesch, C. and $\mathrm{Xu}, \mathrm{Y}$. (2008), "Innovation contests, open innovation, and multiagent problem solving”, Management Science, Vol. 54 No. 9, pp. 1529-1543.

Thomke, S.H. (2003), Experimentation Matters: Unlocking the Potential of New Technologies for Innovation, Harvard Business Press.

Tushman, M. and Nadler, D. (1986), “Organizing for innovation”, California Management Review, Vol. 28 No. 3, pp. 74-92.

Urbinati, A., Chiaroni, D., Chiesa, V. and Frattini, F. (2018), "The role of digital technologies in open innovation processes: an exploratory multiple case study analysis", $R \& D$ Management, https://doi.org/10.1111/radm.12313.

Verganti, R. (2009), Design Driven Innovation: Changing the Rules of Competition by Radically Innovating What Things Mean, Harvard Business Press.

Verganti, R. (2017), Overcrowded - Designing Meaningful Products in a World Awash with Ideas, MIT Press, Boston.

Zeratsky, J. (2016), "Sprints are the secret to getting more done", Harvard Business Review, accessed online at https://hbr.org/2016/03/sprints-are-the-secret-to-getting-more-done 